\title{
Relationship between microstructure and mechanical properties of silicon nitride ceramics
}

\author{
M.J. Hoffmann \\ Max-Planck-Institut für Metallforschung, Institut für Werkstoffwissenschaft, \\ Pulvermetallurgisches Laboratorium, Heisenbergstr. 5, D-70569 Stuttgart, Germany
}

\begin{abstract}
The microstructure of silicon nitride ceramics is related to the mechanical properties. It is demonstrated that the room temperature strength and toughness is determined by size and morphology of the $\mathrm{Si}_{3} \mathrm{~N}_{4}$ grains and the grain boundary phase. The high temperature properties are mainly controlled by the composition and properties of the grain boundary. The grain boundary crystallization, as one strategy for the development of high-temperature resistant materials, is analysed with respect to the phase relationships between $\mathrm{Si}_{3} \mathrm{~N}_{4}$ and the additives and the impossibility of a complete devitrification. It is shown that small amounts of impurities in the starting powder can be enriched in thin grain boundary films and degrade the high-temperature properties.
\end{abstract}

\section{Introduction}

Silicon nitride is a highly covalent bonded compound with a low self-diffusion coefficient of the nitrogen atoms of $6.3 \cdot 10^{-20} \mathrm{~cm}^{2} / \mathrm{s}$ at $1400^{\circ} \mathrm{C}$ [1]. Therefore, densification without any sintering additives is nearly impossible. In 1961, Deeley, et al. [2] was the first to report that $\mathrm{Si}_{3} \mathrm{~N}_{4}$ ceramics could be densified by hotpressing with the addition of oxides as sintering additives. The densification is described as a liquid phase sintering process. At higher temperatures, $\mathrm{SiO}_{2}$, which is always present at the surface of the $\mathrm{Si}_{3} \mathrm{~N}_{4}$ particles, reacts with the oxide additives to form an oxide melt and, with increasing temperature, an oxynitride melt by dissolving $\mathrm{Si}_{3} \mathrm{~N}_{4}$. Most $\mathrm{Si}_{3} \mathrm{~N}_{4}$ starting powders contain a high volume fraction (0.9-0.95) of the metastable $\alpha$-modification, which completely dissolves and supersaturates the liquid phase and reprecipates subsequently in the stable $\beta$-modification [3]. Depending upon the composition of the sintering aids, the liquid phase can form an amorphous or a crystalline grain boundary phase during cooling.

During the last decade there is significant progress in improving the mechanical properties of silicon nitride ceramics at room temperature. The recent advances in improving properties are mainly attributed to improved processing techniques, purer raw materials and the use of gas-pressure sintering or HIP techniques in order to reduce the critical flaw size [4-5]. Furthermore, remarkable effort has been achieved in understanding microstructural development. Today, silicon nitride ceramics can be regarded as a class of material comparable to steel. The different qualities depend on size and shape of the silicon nitride grains and the amount and chemistry of the grain boundary phase. High strength materials exhibit a fine-grained, elongated microstructure, while materials with a high fracture toughness are more coarse grained [5]. In both cases a weak interface is required in order to provide a transgranular fracture mode [6]. The interface strength can be controlled by the composition of the sintering additives which form an amorphous grain boundary layer between silicon nitride grains [7]. However, there seems to be a contradiction between the development of high strength and high-toughness $\mathrm{Si}_{3} \mathrm{~N}_{4}$-ceramics and high-temperature resistant materials because of the fact that the grain boundary is on one hand responsible for the excellent properties at low temperatures, but it limits on the other hand the properties at temperatures above its softening point.

Oyama et al. [8] and Jack et al. [9] tried to overcome the problem of high temperature strength degradation by investigating the solid solution between $\mathrm{Si}_{3} \mathrm{~N}_{4}$ and $\mathrm{Al}_{2} \mathrm{O}_{3}$. The idea is based on an incooperation of the transient liquid phase into the $\mathrm{Si}_{3} \mathrm{~N}_{4}$ crystal structure to form a dense single phase so-called "SiAlON" ceramic without an amorphous grain boundary. The crystal structure of $\beta$-SiAlONs can be derived from the $\beta-\mathrm{Si}_{3} \mathrm{~N}_{4}$ lattice by a simultaneous replacement of $\mathrm{Si}^{4+}$ by $\mathrm{Al}^{3+}$ and $\mathrm{N}^{3-}$ by $\mathrm{O}^{2-}$. Furthermore, Huseby et al. [10] reported the existance of an extented solid solution between $\beta-\mathrm{Si}_{3} \mathrm{~N}_{4}$ and $\mathrm{BeO}$. Other sintering additives such as $\mathrm{MgO}$ or $\mathrm{Y}_{2} \mathrm{O}_{3}$ show no appreciable solubility in the $\beta-\mathrm{Si}_{3} \mathrm{~N}_{4}$ lattice. However, there is a 
remarkable solubility of rare earth ions in $\alpha$-SiAlONs, which can be derived from the $\alpha-\mathrm{Si}_{3} \mathrm{~N}_{4}$ crystal structure. $\alpha$-SiAlONs; which are stable at high temperatures in contrast to $\alpha-\mathrm{Si}_{3} \mathrm{~N}_{4}$, offer the possibility of incorporating the sintering additives and impurities of the starting powders into the structure resulting in a sintered, single-phase ceramic [11] with a better thermal shock resistance [12] and higher hardness, but lower strength and fracture toughness than $\beta-\mathrm{Si}_{3} \mathrm{~N}_{4}$ based materials.

The crystallisation of the amorphous grain boundary phase by a post heat treatment after sintering is, since many years, another strategy for the development of high-temperature resistant $\mathrm{Si}_{3} \mathrm{~N}_{4}$ [13-14]. Nevertheless, grain boundary devitrification leads not always to the desired increase in high-temperature strength above $1200^{\circ} \mathrm{C}$. Very often room as well as high-temperature strength decreases. The temperature dependency of strength is not completely understood, at least due to the quite complicated phase relationships between $\mathrm{Si}_{3} \mathrm{~N}_{4}$ and sintering additives which determine the composition of the grain boundary phase. Furthermore, the theoretical work of Clarke [15] and the HRTEM-investigations of several other authors [16-17] showed that the complete crystallisation of the grain boundary phase cannot be achieved in $\mathrm{Si}_{3} \mathrm{~N}_{4}$ ceramics.

The first part of the present paper describes briefly the microstructural development of $\beta-\mathrm{Si}_{3} \mathrm{~N}_{4}$ based ceramics during sintering. In the second part detailed investigations of the influence of grain boundary crystallisation on mechanical properties such as high-temperature strength and creep resistance of $\mathrm{Yb}_{2} \mathrm{O}_{3}$ containing $\mathrm{Si}_{3} \mathrm{~N}_{4}$ are presented. The advantage of this additive system are the relatively simple phase relationships between $\mathrm{Si}_{3} \mathrm{~N}_{4}-\mathrm{Yb}_{2} \mathrm{O}_{3}-\mathrm{SiO}_{2}$, which offer the opportunity to perform model experiments to study the influence of grain boundary films on the mechanical properties.

\section{Microstructural Development}

The influence of the microstructure of $\beta-\mathrm{Si}_{3} \mathrm{~N}_{4}$ on the mechanical properties has been well-known since 1970 's. The microstructure is characterized by elongated grains with high aspect ratios dispersed in a finegrained, equiaxed matrix, as shown in Fig. 1. The microstructural development can be explained by the crystal structure of $\beta-\mathrm{Si}_{3} \mathrm{~N}_{4}$ and its growth mechanisms [18]. Because of the nearly one-dimensional growth parallel to the crystallographic c-axis it is possible to achieve an "in-situ whisker reinforcement", so that $\mathrm{Si}_{3} \mathrm{~N}_{4}$ ceramics exhibit a higher fracture toughness than other unreinforced structural ceramics. The alternative way to reinforce $\mathrm{Si}_{3} \mathrm{~N}_{4}$ with $\mathrm{SiC}$ whiskers is not a promising route because of the difficulties of obtaining a homogeneous whisker dispersion and densification problems. The needle-like grains can only reinforce the material in case of a predominantly intergranular fracture mode, which means that a propagating crack is running along the grain boundary. The grain boundary phase between two adjacent $\mathrm{Si}_{3} \mathrm{~N}_{4}$ crystals can be controlled by the additive composition and has to be weak enough to achieve the desired fracture mode.

The toughening of $\mathrm{Si}_{3} \mathrm{~N}_{4}$ ceramics seems to be based on crack wake mechanisms such as crack bridging, grain rotation, or pull-out and it scales with (diameter of the elongated grains $)^{1 / 2}$ [7]. The dependency on the aspect ratio of the elongated grains is still not well understood due to the lack of enough experimental data, but observations reveal that coarse grained materials exhibit a higher fracture toughness than fine grained ones and their fracture resistances increases with crack propagation ( $\mathrm{R}$-curve behaviour).

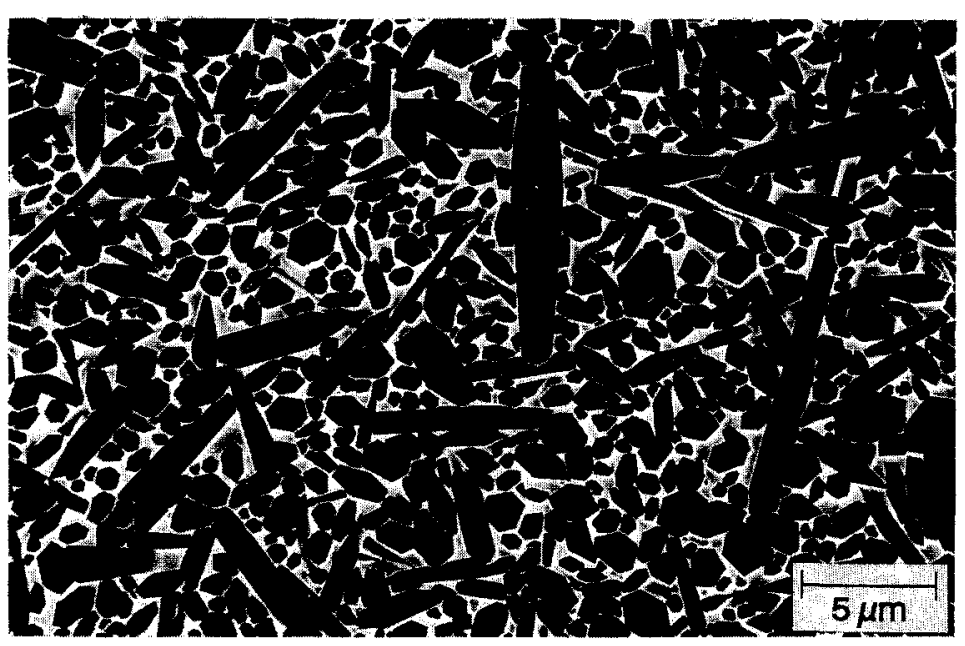

Fig. 1. SEM-micrograph of a typical plasma-etched $\mathrm{Si}_{3} \mathrm{~N}_{4}$ microstructure with elongated $\beta$-grains. 
The size and morphology of the $\mathrm{Si}_{3} \mathrm{~N}_{4}$ grains is controlled by three parameters. The properties of the starting powder, the additive composition, and the sintering conditions. It has been shown in a previous paper that the aspect ratio of the $\beta-\mathrm{Si}_{3} \mathrm{~N}_{4}$ grains is strongly influenced by the number and size of the $\beta$ seeds of the starting powder. After complete transformation from $\alpha$ - to $\beta-\mathrm{Si}_{3} \mathrm{~N}_{4}$ grain growth starts by dissolution of smaller grains. The maximum aspect ratio of the large grains is determined by the diameter distribution and the frequency of grain impingement in the transformation and grain growth stage [19].

\section{Analysis of the Grain Boundary Phase}

Silicon nitride ceramics exhibit a multiphase microstructure as indicated from Fig. 1. The micrograph reveals the $\mathrm{Si}_{3} \mathrm{~N}_{4}$ grains and between them either a completely amorphous or a partially crystalline grain boundary phase. The influence of these grain boundary phase on the mechanical properties at room as well as high temperatures will be discussed in the following chapters. The analysis is based on model experiments of $\mathrm{Si}_{3} \mathrm{~N}_{4}$ densified with various amounts of the sintering additives $\mathrm{Yb}_{2} \mathrm{O}_{3}$ and $\mathrm{SiO}_{2} . \mathrm{Yb}_{2} \mathrm{O}_{3}$. fluxed $\mathrm{Si}_{3} \mathrm{~N}_{4}$ ceramics have become quite interesting due to their higher oxidation resistance and the improved densification behaviour in comparison to $\mathrm{Si}_{3} \mathrm{~N}_{4}$ with yttria or other rare earth oxides as sintering additive. Some of the materials investigated in this study contain additionally small amounts of $\mathrm{CaO}$ as model impurity and $\mathrm{Al}_{2} \mathrm{O}_{3}$ for an enhanced sinterability as well as a modifier of the grain boundary composition.

\section{Subsolidus Phase Relationships of the System $\mathrm{Si}_{2} \mathrm{~N}_{4}-\mathrm{SiO}_{2}=\mathrm{Yb}_{2} \mathrm{O}_{3}$}

At first the subsolidus phase diagram of the pseudoternary system $\mathrm{Si}_{3} \mathrm{~N}_{4}-\mathrm{SiO}_{2}-\mathrm{Yb}_{2} \mathrm{O}_{3}$ is considered. The system shows one pseudoternary phase $\left(\mathrm{Yb}_{4} \mathrm{Si}_{2} \mathrm{O}_{7} \mathrm{~N}_{2}\right)$ and the three pseudobinary phases $\mathrm{Yb}_{2} \mathrm{Si}_{2} \mathrm{O}_{7}$, $\mathrm{Yb}_{2} \mathrm{SiO}_{5}$, and $\mathrm{Si}_{2} \mathrm{~N}_{2} \mathrm{O}_{2}$ (Fig. 2). In the well-known yttria-related diagram [20] and other rare earth oxide related systems exist four nitrogen containing, pseudoternary phases. The reason for the instability of the apatite- $\left(\mathrm{Y}_{10}\left(\mathrm{SiO}_{4}\right)_{6} \mathrm{~N}_{2}\right)$, wollastonite- $\left(\mathrm{YSiO}_{2} \mathrm{~N}\right)$, and melillite- $\left(\mathrm{Y}_{2} \mathrm{Si}_{3} \mathrm{O}_{3} \mathrm{~N}_{4}\right)$ phase in the $\mathrm{Yb}$-system is attributed to the smaller cation radius of the $\mathrm{Yb}^{3+}$-ion $(85.8 \mathrm{pm})$ in comparison to $\mathrm{Y}^{3+}(89.3 \mathrm{pm})$. An analysis of the different crystal structures of all four pseudoternary phases in the Y-related system showed that the wöhlerite phase $\left(\mathrm{Y}_{4} \mathrm{Si}_{2} \mathrm{O}_{7} \mathrm{~N}_{2}\right)$ is the only structure which can tolerate a wide variation of radii of interstitial cations. However, the $\mathrm{Yb}$-system has the advantage that both silicate phases $\left(\mathrm{Yb}_{2} \mathrm{Si}_{2} \mathrm{O}_{7}\right.$ and $\mathrm{Yb}_{2} \mathrm{SiO}_{5}$ ) can be crystallized as a grain boundary phase in $\mathrm{Si}_{3} \mathrm{~N}_{4}$-ceramics in contrast to other additive systems.
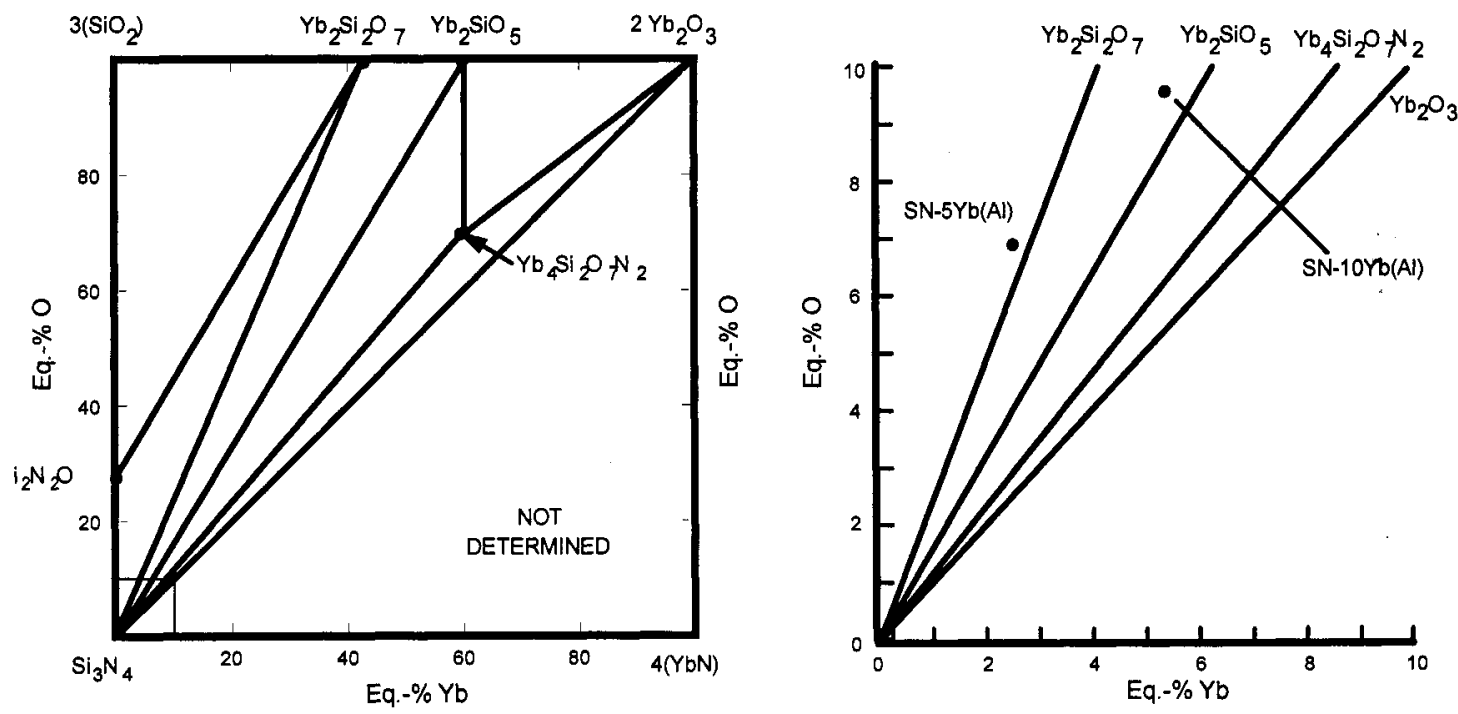

Figure 2. Subsolidus phase relationships of the $\mathrm{Si}_{3} \mathrm{~N}_{4}-\mathrm{SiO}_{2}-\mathrm{Yb}_{2} \mathrm{O}_{3}-\mathrm{YbN}$ system and sample compositions. 
Most of the silicon nitride ceramics have an additive content smaller than 10 eq. $\%$ and the overall compositions are, therefore, located in the marked square in the $\mathrm{Si}_{3} \mathrm{~N}_{4}$-rich corner. For the final phase relationship between the $\mathrm{Si}_{3} \mathrm{~N}_{4}$ matrix and the grain boundary phase, the $\mathrm{SiO}_{2}$ content of the $\mathrm{Si}_{3} \mathrm{~N}_{4}$ powder and the oxygen pick-up during processing has to be taken into account since small changes in oxygen content can cause changes in phase relationships. The marked area is enlarged in the diagram on the right hand side and shows the position of the investigated compositions. The samples denoted in the following chapters as $\mathrm{SN}-5 \mathrm{Yb}(\mathrm{Al})$ contains 5 vol. $\% \mathrm{Yb}_{2} \mathrm{O}_{3}$ and $0.5 \mathrm{wt.} \% \mathrm{Al}_{2} \mathrm{O}_{3}$ as sintering additive and SN$10 \mathrm{Yb}(\mathrm{Al})$ was densified with $10 \mathrm{vol} . \% \mathrm{Yb}_{2} \mathrm{O}_{3}$ and $0.5 \mathrm{wt} . \% \mathrm{Al}_{2} \mathrm{O}_{3}$. It has to be considered that the diagram represents only the projection of $\mathrm{Al}_{2} \mathrm{O}_{3}$-containing sample compositions on the $\mathrm{Si}_{3} \mathrm{~N}_{4}-\mathrm{SiO}_{2}-\mathrm{Yb}_{2} \mathrm{O}_{3}-\mathrm{YbN}$ plane. Since $\mathrm{Al}_{2} \mathrm{O}_{3}$ is not included in the diagram, phase relationships may be changed by the crystallisation of $\mathrm{Al}_{2} \mathrm{O}_{3}$-containing phases.

\section{Grain Boundary Devitrification}

Figure 3 shows the microstructure of the gas pressure sintered specimens $\mathrm{SN} 5 \mathrm{Yb}(\mathrm{Al})$ and $\mathrm{SN} 10 \mathrm{Yb}(\mathrm{Al})$. The $\mathrm{SN} 10 \mathrm{Yb}(\mathrm{Al})$-samples with the higher additive content reveals a better sinterability and exhibit a coarser microstructure with a significant higher volume content of thick and elongated grains.
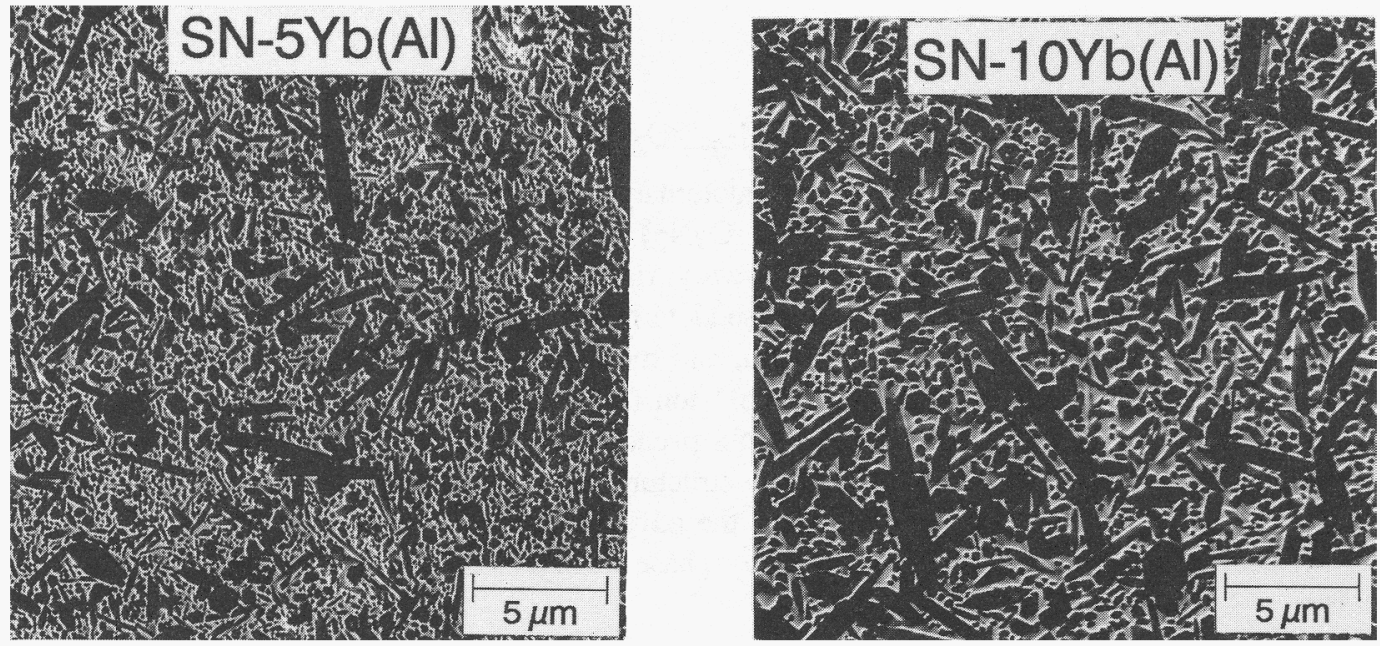

Figure 3. SEM micrograph of the gas pressure sintered $\mathrm{SN} 5 \mathrm{Yb}(\mathrm{Al})$ and $\mathrm{SN} 10 \mathrm{Yb}(\mathrm{Al})$ samples.

$\mathrm{X}$-ray investigations of the as sintered $\mathrm{SN} 10 \mathrm{Yb}(\mathrm{Al})$-material reveal a crystalline $\mathrm{Yb}$-rich secondary phase with the composition $5 \mathrm{Yb}_{2} \mathrm{O}_{3} \cdot \mathrm{Al}_{2} \mathrm{O}_{3} \cdot \mathrm{SiO}_{2}$ (5:1:1-phase). More detailed TEM-investigations show an incomplete crystallisation with approximately $30 \mathrm{vol} . \% \mathrm{SiO}_{2}$-rich glass. This residual glass reacts during a post heat treatment at $1250^{\circ} \mathrm{C}$ for $12 \mathrm{~h}$ with the 5:1:1-phase to form the two stable silicate phases $\mathrm{Yb}_{2} \mathrm{Si}_{2} \mathrm{O}_{7}$ and $\mathrm{Yb}_{2} \mathrm{SiO}_{5}$, as expected from the phase diagram (Fig. 2). The TEM-observations reveal now a nearly complete devitrification of the triple junctions. However, there is still an amorphous grain boundary film left between the second phases and $\mathrm{Si}_{3} \mathrm{~N}_{4}$ and between two adjacent $\mathrm{Si}_{3} \mathrm{~N}_{4}$ grains [21] as schematically shown in Figure 4. X-ray investigations of the $\mathrm{SN} 5 \mathrm{Yb}(\mathrm{Al})$-samples reveal an amorphous grain boundary phase after sintering and the crystallisation of the disilicate $\mathrm{Yb}_{2} \mathrm{Si}_{2} \mathrm{O}_{7}$ during post-heat treatment. TEMinvestigations give a degree of crystallisation of approximately $70 \mathrm{vol} . \%$. An incomplete crystallization can be attributed to the volume change during crystallisation of the amorphous phase which set up hydrostatic stresses. The strain energy associated with it could oppose a further devitrification [22].

The intergranular film thickness between $\mathrm{Si}_{3} \mathrm{~N}_{4}$-grains of the $\mathrm{SN} 5 \mathrm{Yb}(\mathrm{Al})$ and $\mathrm{SN} 10 \mathrm{Yb}(\mathrm{Al})$-samples is 1 $\mathrm{nm}$ and it can be assumed that the chemical composition of the amorphous film is the same for both materials [23]. 
as sintered

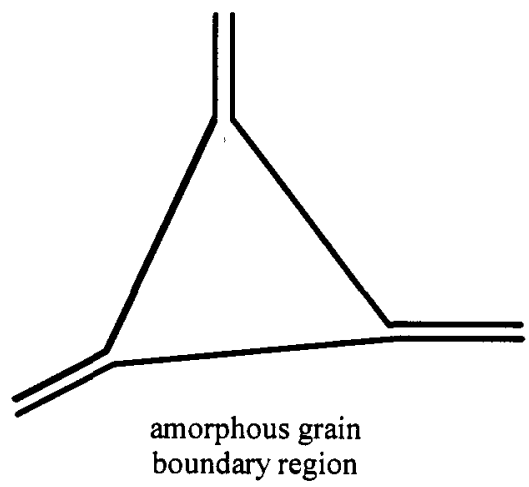

annealed

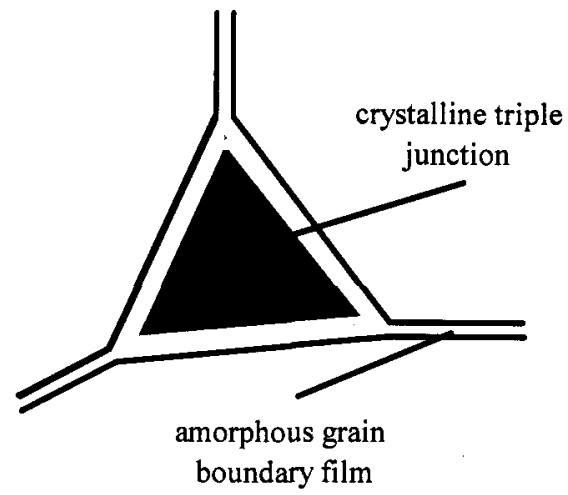

Figure 4. Schematics of an amorphous triple junction after sintering and a "completely" crystallized triple junction after heat treatment.

Figure 5 shows a comparison of the bending strength of the as sintered and annealed $\mathrm{SN} 5 \mathrm{Yb}(\mathrm{Al})$ and $\mathrm{SN} 10 \mathrm{Yb}(\mathrm{Al})$ samples. Despite the better sinterability, the room temperature strength of the as sintered $\mathrm{SN} 10 \mathrm{Yb}(\mathrm{Al})$ is lower than that of $\mathrm{SN} 5 \mathrm{Yb}(\mathrm{Al})$, but the first detectable strength decrease with increasing temperature is for the $\mathrm{SN} 10 \mathrm{Yb}(\mathrm{Al})$ composition approximately $200^{\circ} \mathrm{C}$ higher than for $\mathrm{SN} 5 \mathrm{Yb}(\mathrm{Al})$. Both materials behave similar in the temperature regime above $1000^{\circ} \mathrm{C}$. The strength-temperature curves of the annealed samples reveal a characteristic decrease between 800 and $1000^{\circ} \mathrm{C}$ and a plateau between 1000 and $1200^{\circ} \mathrm{C}$. Crystallisation of the grain boundary causes a significant strength decrease at room temperature for both compositions. However, the strength decrease is larger for $\mathrm{SN} 5 \mathrm{Yb}(\mathrm{Al})$ with the amorphous grain boundary after sintering than for $\mathrm{SN} 10 \mathrm{Yb}(\mathrm{Al})$, which already had a partially crystalline grain boundary phase. Furthermore, it has to be pointed out that the high-temperature strength of the $\mathrm{SN} 10 \mathrm{Yb}(\mathrm{Al})$ sample can be improved by a post heat treatment, while the strength of $\mathrm{SN} 5 \mathrm{Yb}(\mathrm{Al})$ is, at $1350^{\circ} \mathrm{C}, 150 \mathrm{MPa}$ lower than the as sintered material.

The strength degradation at room temperature of
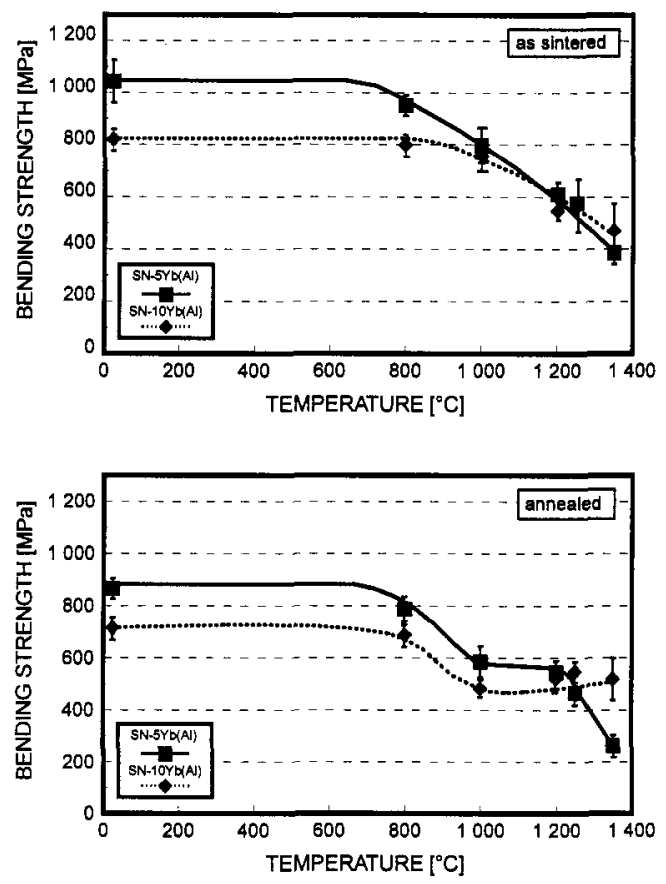

Figure 5. Bending strength as a function of temperature

$\mathrm{Si}_{3} \mathrm{~N}_{4}$ materials with a crystalline grain boundary

phase is caused by the formation of internal stresses during the devitrification of the grain boundary [22]. The crystallisation of a glass is generally combined with a reduction of the volume due to the higher density of crystalline phases. The volume change leads to the generation of radial tensile stresses in the triple junctions at the interface between $\mathrm{Si}_{3} \mathrm{~N}_{4}$ and the secondary phase. These stresses can only be relaxed by a mass transport of $\mathrm{Si}_{3} \mathrm{~N}_{4}$ through the grain boundary film to the triple junctions. However, the annealing temperature of $1250^{\circ} \mathrm{C}$ is relatively low for a remarkable solution and reprecipitation of $\mathrm{Si}_{3} \mathrm{~N}_{4}$. A stress relaxation by viscous flow of material from two-grain junctions to triple junctions in microstructures with a "complete" crystallisation, as it is the case for $\mathrm{SN} 10 \mathrm{Yb}(\mathrm{Al})$, would required a change of the intergranular film thickness during the post heat treatment. This could not be observed by HRTEM. 


\section{Grain Boundary Film Chemistry}

The disilicate $\mathrm{Yb}_{2} \mathrm{Si}_{2} \mathrm{O}_{7}$ is a stochiometric compound and has only a minor solubility for $\mathrm{Al}_{2} \mathrm{O}_{3}$ and $\mathrm{CaO}$. The composition $\mathrm{SN} 5 \mathrm{Yb}(\mathrm{Al})$ with the amorphous grain boundary phase after sintering and the crystalline phase $\mathrm{Yb}_{2} \mathrm{Si}_{2} \mathrm{O}_{7}$ after annealing offers, therefore, the opportunity to study the influence of the grain boundary film chemistry on the high-temperature properties. The analysis is based on three slightly different compositions with 5 vol.\% $\mathrm{Yb}_{2} \mathrm{O}_{3}$ and various amounts of "model" impurities. The sample $\mathrm{SN} 5 \mathrm{Yb}$ contains only $\mathrm{Yb}_{2} \mathrm{O}_{3}, \mathrm{SN} 5 \mathrm{Yb}(\mathrm{Al}) 5$ vol. $\% \mathrm{Yb}_{2} \mathrm{O}_{3}$ and 0.5 wt.\% $\mathrm{Al}_{2} \mathrm{O}_{3}$, and $\mathrm{SN} 5 \mathrm{Yb}(\mathrm{Al}, \mathrm{Ca})$ has beside 5 vol. $\% \mathrm{Yb}_{2} \mathrm{O}_{3}$ and $0.5 \mathrm{wt} \% \mathrm{Al}_{2} \mathrm{O}_{3}$ small amounts of $\mathrm{CaO}(0,07 \mathrm{wt} . \%)$. All three compositions reveal a similar $\mathrm{Si}_{3} \mathrm{~N}_{4}$ grain size and morphology. $\mathrm{XRD}$-investigations confirm the amorphous grain boundary after sintering and it is assumed that $\mathrm{Al}_{2} \mathrm{O}_{3}$ as well as $\mathrm{CaO}$ is homogeneously distributed in the grain boundary region. All three samples show the crystallization of $\mathrm{Yb}_{2} \mathrm{Si}_{2} \mathrm{O}_{7}$ during annealing. The volume content of the residual glass is approximately $30 \%$, as observed by TEM.

Figure 6 shows the bending strength of the as sintered and annealed samples as a function of temperature. The as sintered materials reveal nearly no difference at temperatures above $1000^{\circ} \mathrm{C}$ and relatively small differences at room temperature, due to the different sinterability and the corresponding larger critical flaw size. Despite the typical plateau in the strength temperature curves near $1000^{\circ} \mathrm{C}$, the annealed specimens behave quite different. The temperature dependence of strength for the SN5Yb(Al) composition has already been discussed in the previous chapter. $\mathrm{SN} 5 \mathrm{Yb}$ without $\mathrm{Al}_{2} \mathrm{O}_{3}$ reveals the best high temperature strength with $\sigma>500 \mathrm{MPa}$ upto $1350^{\circ} \mathrm{C}$, but it exhibits a strength decrease of more than $200 \mathrm{MPa}$ between 600 and $800^{\circ} \mathrm{C}$. $\mathrm{SN} 5 \mathrm{Yb}(\mathrm{Al}, \mathrm{Ca})$ with $\mathrm{Al}_{2} \mathrm{O}_{3}$ and $700 \mathrm{ppm} \mathrm{CaO}$ has the lowest strength of all three samples at temperatures above $800^{\circ} \mathrm{C}$.
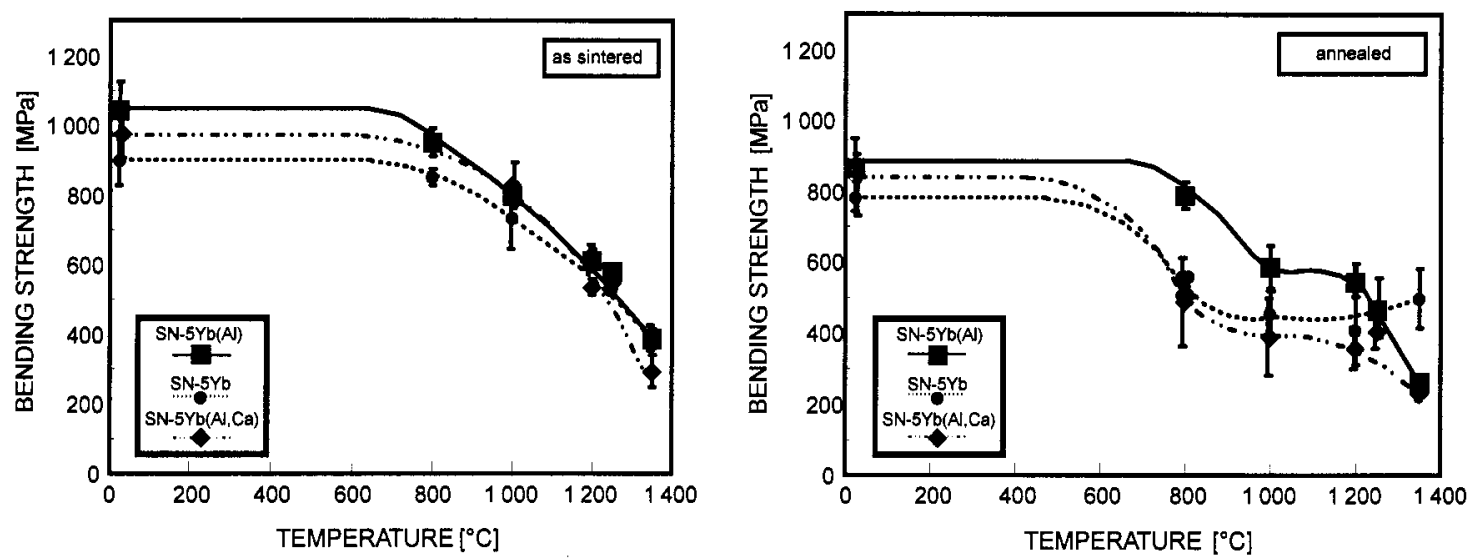

Figure 6. Bending strength as a function of temperature after sintering and annealing.

The creep deformation at $1200^{\circ} \mathrm{C}$ and $100 \mathrm{MPa}$ (Fig. 7) reflects the strengthtemperature behaviour. $\mathrm{SN} 5 \mathrm{Yb}$ without $\mathrm{Al}_{2} \mathrm{O}_{3}$ reveals the best strength at elevated temperatures and has also the best creep resistance with strains of less than $0.04 \%$ after $90 \mathrm{hrs}$. Nevertheless, the strain rate in the secondary creep regime is similar to $\mathrm{SN} 5 \mathrm{Yb}(\mathrm{Al})$, which shows a more pronouced primary creep deformation. The CaO-containing material has the highest creep deformation of $0.4 \%$ after $70 \mathrm{hrs}$.

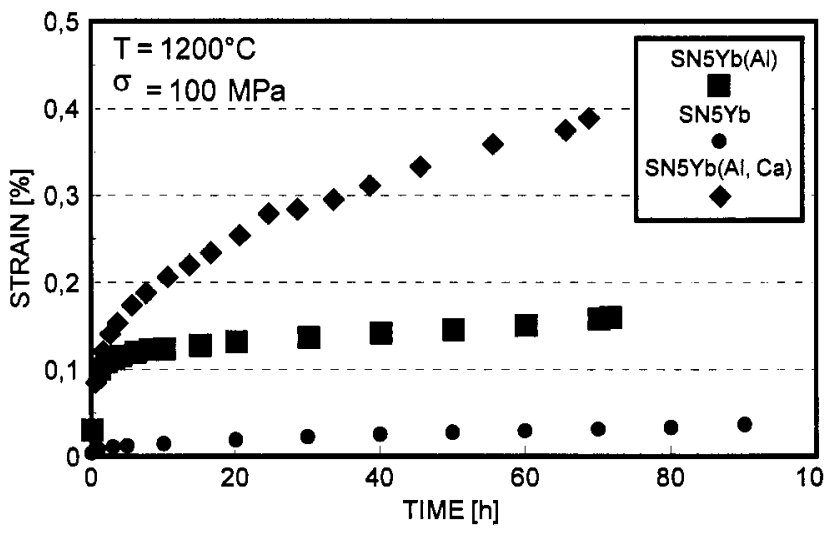

Figure 7. Creep behaviour of annealed specimens. 
The difference in high-temperature strength as well as in creep behaviour must be mainly controlled by the amorphous grain boundary film since all three materials contain the same grain boundary phase $\mathrm{Yb}_{2} \mathrm{Si}_{2} \mathrm{O}_{7}$ and comparable amounts of residual glass. The "structure" of these films between two $\mathrm{Si}_{3} \mathrm{~N}_{4}$ grains is schematically shown in Figure 8. Under the assumption of an adsorption layer of Si-O-N-tetrahedra on each side of the $\mathrm{Si}_{3} \mathrm{~N}_{4}$ grains, there is only space enough for maximum 1-2 additional Si-O-N-tetrahedra in a film of 1-2 nm thickness. The Si-O-N-tetrahedra are connected by cations of the sintering additives. Kleebe et al. [24] found that the thickness of these films are very sensitive to their chemical composition, but there seems to be no simple correlation between the thickness $(\mathrm{t})$ itself and the high-temperature properties.

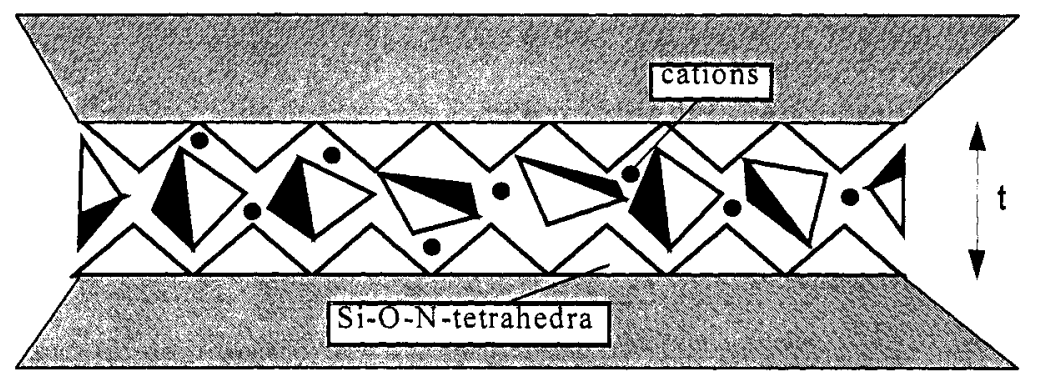

Figure 8. Schematics of a grain boundary film between adjcent $\mathrm{Si}_{3} \mathrm{~N}_{4}$ grains.

The present samples had a similar film thickness of 1 to $1.1 \mathrm{~nm}$ after sintering. This indicates a similar chemical composition of the grain boundary and a homogeneous distribution of $\mathrm{Al}_{2} \mathrm{O}_{3}$ and $\mathrm{CaO}$ in the glass. During annealing neither $\mathrm{Al}_{2} \mathrm{O}_{3}$ nor $\mathrm{CaO}$ can be dissolved in $\mathrm{Yb}_{2} \mathrm{Si}_{2} \mathrm{O}_{7}$. Consequently, they had to be enriched in the residual amorphous phase. The enrichment of $\mathrm{CaO}$ in the grain boundary film of the $\mathrm{SN} 5 \mathrm{Yb}(\mathrm{Al}, \mathrm{Ca})$ sample is detectable by measurements of the film thickness, which changes from $1.1 \mathrm{~nm}$ after sintering to $1.5 \mathrm{~nm}$ after annealing [24]. Kleebe et al. [25] explained the increase in film thickness with increasing $\mathrm{CaO}$ concentrations by structural changes in the amorphous layer due to the nature of $\mathrm{CaO}$ as a network modifier. $\mathrm{Al}_{2} \mathrm{O}_{3}$ can act as a network modifier or a network former, but the formation of ( $\mathrm{Si}, \mathrm{Al}$ )O-tetrahedra is most reasonable and would explain the constant film thickness in SN5Yb and SN5Yb(Al) samples before and after annealing.

Strength measurements show that $\mathrm{Al}_{2} \mathrm{O}_{3}$ enhances the strength in the intermediate temperature regime between 600 and $1000^{\circ} \mathrm{C}$. The influence of $\mathrm{Al}_{2} \mathrm{O}_{3}$ is not well understood, but it seems to strengthen the grain boundary in comparison to a pure $\mathrm{SiO}_{2} / \mathrm{Yb}_{2} \mathrm{O}_{3}$ composition. However, the $\mathrm{Al}_{2} \mathrm{O}_{3}$ containing material reveals a lower strength than the $\mathrm{Al}_{2} \mathrm{O}_{3}$ free one, if the failure mechanism changes from subcritical to creep crack growth at temperatures $>1200^{\circ} \mathrm{C}$. This effect is relatively easy to understand if one considers the decrease in viscosity of aluminosilicate glasses against silica. The addition of $\mathrm{CaO}$ compensates the grain boundary strengthening by $\mathrm{Al}_{2} \mathrm{O}_{3}$ in the intermediate temperature range so that the material has a similar behaviour as $\mathrm{SN} 5 \mathrm{Yb}$. Since small amounts of $\mathrm{CaO}$ can cause a decrease in the viscosity of glasses of several orders of magnitude, the properties above $1200^{\circ} \mathrm{C}$ are not surprising.

\section{Summary}

$\mathrm{Si}_{3} \mathrm{~N}_{4}$ ceramics were analysed with respect to their microstrcuture development. It has been discussed that the grain size and morphology of the $\mathrm{Si}_{3} \mathrm{~N}_{4}$ grains determine the fracture toughness of the material at room temperature as long as an intergranular fracture mode is provided by a weak interface between $\mathrm{Si}_{3} \mathrm{~N}_{4}$ and the grain boundary phase. The analysis of the grain boundary phase reveals that careful processing has to been performed to obtain the desired crystalline grain boundary phase and a maximum degree of crystallisation. However, a complete devitrification of the amorphous grain boundary in silicon nitride ceramics is not possible. The chemistry of the residual amorphous grain boundary films dominate the mechanical properties at higher temperatures. This effect was demonstrated by a model experiment with small quantities of $\mathrm{CaO}(700 \mathrm{ppm})$ and $\mathrm{Al}_{2} \mathrm{O}_{3}(0.5 \mathrm{wt} \%)$. The crystallization of a stochimetric grain boundary phase caused an enrichment of the $\mathrm{Al}_{2} \mathrm{O}_{3}$ - and $\mathrm{CaO}$ "impurities" in the residual grain boundary films and determines strength as well as creep behaviour at higher temperatures. 


\section{Acknowledgement}

The author would like to thank E. Hampp, R.M. Cannon and G.A. Schneider for their helpful discussions. A part of the work was financially supported by the German Ministry of Science and Technology (BMFT) under contract number 03 M 2012.

\section{References}

[1] K. Kijama and S. Shirasaki, Nitrogen Self Diffusion in Silicon Nitride", J.Chem.Phys., 65, 2668, (1976).

[2] G.C. Deeley, J.M. Herbert and N.C. Moore, "Dende Silicon Nitride", Pow.Met., 8, 145, (1961).

[3] J. Weiss and W.A. Kaysser, "Liquid Phase Sintering", in: F.L. Riley (ed.), Progress in Nitrogen Ceramics, Martinus Nijhoff Publ., Boston, 169, (1983).

[4] M.J. Hoffmann, P.F. Becher and G. Petzow (eds.), "Silicon Nitride 93", Key Engineering Materials, Vol. 89-91, Trans Tech Publications, Switzerland, (1993).

[5] Yo Tajima, "Development of High-Performance Silicon Nitride Ceramics and their Applications", in: I.W. Chen et al. (eds.), Silicon Nitride-Scientific and Technological Advances, MRS Symposium Proceedings, Vol. 287, MRS Pittsburgh (USA), 189 (1993).

[6] K. Urashima, Y. Tajima and M. Watanabe, "R-Curve and Fatigue Behaviour of Gas Pressure Sintered Silicon Nitride", in: R.C. Bradt et. al. (eds.), Fracture Mechanics of Ceramics, Vol. 9, Plenum Press, New York, 235, (1992).

[7] P.F. Becher, S.L. Hwang, H.T. Lin, and T.N. Tiegs, "Microstructural Contribution to the Fracture Resistance of Silicon Nitride Ceramics", to be published in: M.J. Hoffmann and G. Petzow, "Tailoring of Mechanical Properties of $\mathrm{Si}_{3} \mathrm{~N}_{4}$ Ceramics", NATO ASI Series, Kluwer Academic Press, (1994).

[8] Y. Oyama, O. Kamigato, "Solid Solubility of Some Oxides in $\mathrm{Si}_{3} \mathrm{~N}_{4}$ ", Japan.J.Appl.Phys., 1673, (1971).

[9] K.H. Jack and W.J. Wilson, "Ceramics Based on the Si-Al-O-N- Related Systems", Nature.Phys.Sci., 238, 28, (1982).

[10] J. Huseby, H.L. Lukas, G. Petzow, "Phase Equillibria in the System $\mathrm{Si}_{3} \mathrm{~N}_{4}-\mathrm{SiO}_{2}-\mathrm{BeO}_{-} \mathrm{Be}_{2} \mathrm{~N}_{3}$ ", J.Am.Ceram.Soc., 58, 377, (1982).

[11] K.H. Jack, "The Crystal Chemistry of the SiAlONs and related Ceramics", in: F.L. Riley (ed.), "Progress in Nitrogen Ceramics", Martinus Nijhoff Publ., Boston, 109, (1983).

[12] M. Mitomo, H. Tanaka, U. Muramatsu and Y. Futjii, "The Strength of $\alpha$-SiAlON Ceramics", J.Mater.Sci. Letters 15, 2661, (1980).

[13] M.H. Lewis, "SiAlONs and Silicon Nitrides; Microstructural Design and Performance", in: I.W. Chen et al. (eds.), Silicon Nitride-Scientific and Technological Advances, MRS Symposium Proceedings, Vol. 287, MRS Pittsburgh (USA), (1993), 159.

[14] P. Greil, "High-Temperature Strengthening of Silicon Nitride Ceramics", in: D. Taylor (ed.), Science of Ceramics 14, Stoke-on-Trent, (1987), 645.

[15] D.R. Clarke, "On the Equilibrium Thickness of Intergranular Glass Phases in Ceramics Materials", J.Amer.Ceram.Soc., Vol. 70, [1], (1987), 15.

[16] H.-J. Kleebe, M.J. Hoffmann, and M. Rühle, "Influence of secondary Phase Chemistry on Grain Boundary Film Thickness in Silicon Nitride", Z.Metallkde, 83, [8], 610, (1992).

[17] D.R. Clarke, G. Thomas, "Grain boundary Phases in a Hot-Pressed MgO Fluxed Silicon Nitride", J.Amer. Ceram. Soc., 60, [11-12], 491, (1977).

[18] M.Krämer, M.J. Hoffmann and G. Petzow, "Grain Growth Kinetics of $\mathrm{Si}_{3} \mathrm{~N}_{4}$ During $\alpha / \beta$-Transformation", Acta metall. mater., Vol.41, No. 10, 2939, (1993).

[19] M.J. Hoffmann, G. Petzow, "Tailored microstructures of Silicon Nitride Ceramics", to be published in Pure and Applied Chemistry, September issue, (1994).

[20] L.J. Gaukler, H.Hohnke and T.Y. Tien, "The System $\mathrm{Si}_{3} \mathrm{~N}_{4}-\mathrm{SiO}_{2}-\mathrm{Y}_{2} \mathrm{O}_{3}$ ", J.Am.Ceram.Soc., 63, 35, (1973).

[20] J.S. Vetrano, H.-J. Kleebe, E. Hampp, M.J. Hoffmann, and R.M. Cannon, "Epitaxial Deposition of Silicon Nitride During Post-Sintering Heat Treatment", J.Mater.Sci.Letters, 11, 1249, (1992).

[21] W. Pompe, H. Kessler, "Internal Stresses in Silicon Nitride and Their Influence on Mechanical Behaviour", to be published in: M.J. Hoffmann and G. Petzow, "Tailoring of Mechanical Properties of $\mathrm{Si}_{3} \mathrm{~N}_{4}$ Ceramics", NATO ASI Series, Kluwer Academic Press, (1994).

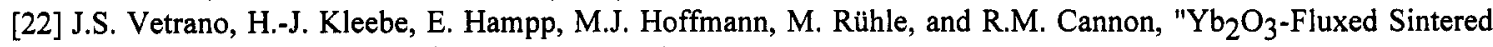
Silicon Nitride", J.Mater. Sci., 28, (1993), 3529.

[23] H.-J. Kleebe, M.K. Cinibulk, I. Tanaka, J. Bruley, J.S. Vetrano, and M. Rühle, "High Resolution Electron Microscopy Studies on Silicon Nitride Ceramics",, to be published in: M.J. Hoffmann and G. Petzow, "Tailoring of Mechanical Properties of $\mathrm{Si}_{3} \mathrm{~N}_{4}$ Ceramics", NATO ASI Series, Kluwer Academic Press, (1994).

[24] H-J. Kleebe, M.K. Cinibulk, I. Tanaka, J. Bruley, R.M. Cannon, D.R. Clarke, M.J. Hoffmann, and M. Rühle, "High-Resolution Electron Microscopy Observations of Grain Boundary Films in Silicon Nitride Ceramics", in I.W. Chen et al. (eds.), Silicon Nitride-Scientific and Technological Advances, MRS Symposium Proceedings, Vol. 287, MRS Pittsburgh (USA), (1993), 65. 